\title{
The Effect of Sex Hormones on Peroxisome Proliferator-Activated Receptor Gamma Expression and Activity in Mature Adipocytes
}

\author{
Hiromi Sato,* Hana Sugai, Hiroshi Kurosaki, Momoko Ishikawa, Asami Funaki, \\ Yuki Kimura, and Koichi Ueno \\ Department of Geriatric Pharmacology and Therapeutics, Graduate School of Pharmaceutical Sciences, Chiba \\ University; 1-8-1 Inohana, Chuou-ku, Chiba 260-8675, Japan. \\ Received October 3, 2012; accepted January 10, 2013
}

Peroxisome proliferator-activated receptor (PPAR) $\gamma$ plays a major role in the regulation of lipid and carbohydrate metabolism. Pioglitazone is a PPAR $\gamma$ agonist that is widely used for the treatment of type 2 diabetes mellitus. However, female patients have been reported to experience stronger efficacy and adverse effects than male patients. This study evaluated the effects of sex hormones on PPAR $y$ expression and activity in adipocytes. Mouse 3T3-L1 preadipocytes were used after being grown into matured adipocytes. The sex hormones $17 \beta$-estradiol (E2), testosterone (T), or $5 \alpha$-androstan-17 $\beta$-ol-3-one (dihydrotestosterone; DHT) were added to the matured adipocytes and the cells were then maintained for short (24-72 h) or long (1- or 2-weeks) periods. E2 significantly upregulated PPAR $\gamma$ protein expression in a concentration-dependent manner after extended exposure, whereas $T$ and DHT did not have such an effect. When cells were co-treated with pioglitazone and E2, PPARy protein expression significantly increased in an E2-dependent manner, whereas this expression seemed to be reduced by pioglitazone mono-treatment and co-treatment with DHT at higher concentrations. The secretion levels of adiponectin protein, a major indicator of PPAR $\gamma$ activity, were significantly decreased by DHT, but were not affected by E2. Finally a luciferase assay was performed using a PPAR response element- $L u k$ reporter gene. Transcriptional activity was not changed by any of single sex hormone treatment, but was significantly downregulated by co-treatment with pioglitazone and DHT. Taken together, our results suggest that sex hormones may influence PPARy expression and function, which may explain the observed sex-specific different effect of pioglitazone.

Key words estrogen; dihydrotestosterone; peroxisome proliferator-activated receptor $\gamma$; adipocyte; pioglitazone; diabetes

Peroxisome proliferator-activated receptors (PPARs) are known to play a major clinical role in the etiopathogenesis of metabolic diseases such as diabetes mellitus (DM), arteriosclerosis, cardiovascular pathologies, and cancer. ${ }^{1)}$ PPARs are transcriptional factors that are activated by fatty acids and eicosanoids. ${ }^{2)}$ When a ligand binds PPAR, it heterodimerizes with the retinoid-X-receptor and binds to PPAR response elements (PPREs) located in the promoters of target genes. ${ }^{3,4)}$ PPAR subtypes (PPAR $\alpha, \operatorname{PPAR} \gamma$, and $\operatorname{PPAR} \delta$ ) have distinct tissue localization and physiological activities. Of these, $\operatorname{PPAR} \gamma$ is the predominant subtype in adipose tissue, where lipid remodeling and adipocyte differentiation take place. $\operatorname{PPAR} \gamma$ plays a key role in lipid storage and also influences carbohydrate metabolism indirectly. ${ }^{5}$

There are 2 isotypes of PPAR $\gamma, \operatorname{PPAR} \gamma 1$ and PPAR $\gamma 2$. According to previous studies, PPAR $\gamma 2$ may be an important factor in the pathogenesis of obesity and diabetes. ${ }^{6,7)}$ Previously, we reported higher expression of PPAR $\gamma 2$ than PPAR $\gamma 1$ in rat adipose tissue. ${ }^{8}$ Interestingly, the expression of PPAR $\gamma 2$ in perigonadal adipose tissues was found to be significantly higher in females than in males. Moreover, the expression of PPAR $\gamma 2$ in female perigonadal adipose tissue significantly decreased during diestrus. These findings suggest that sex hormones might affect the expression of PPAR $\gamma 2$ in adipose tissues.

Pioglitazone is a potent PPAR $\gamma$ agonist that is widely used in patients with type $2 \mathrm{DM}$, in which insulin resistance is the major obstacle for treatment. It is also well known that

The authors declare no conflict of interest. the pharmacological effect of pioglitazone differs between the sexes. Therefore, a $30-\mathrm{mg}$ daily dose of pioglitazone is recommended in men, whereas only $15 \mathrm{mg}$ is recommended in women because the drug's effect is stronger in females and its adverse effects, such as edema, occur more frequently in women than in men. ${ }^{9)}$ Fujita et al. reported the possibility that sex differences in the pharmacokinetics of this drug were one of the causes of these differences. ${ }^{10)}$ Another reason for these differences may be the difference in the distribution of adipose tissue between males and females. Females have a higher percentage of body fat and tend to accumulate more subcutaneous fat than males, whereas males have a lower percentage of body fat and accumulate more visceral fat. ${ }^{11)}$ Testosterone (T) transports extra fat to abdominal adipose, whereas estrogen removes it to make room around the uterus for pregnancy. Indeed, Ley et al. demonstrated that postmenopausal women had more total fat than premenopausal women. ${ }^{12)}$ Despite the higher level of body fat, female humans and rodents are not only more insulin-sensitive than males, but they are also more resistant to fatty-acid-induced insulin resistance. ${ }^{13-15)}$ In contrast, Macotela et al. showed that castration in male mice resulted in increased insulin sensitivity in both intra-abdominal/ perigonadal and subcutaneous adipose depots, and therefore, T may exert an inhibitory effect on insulin sensitivity. ${ }^{11)}$

Several studies have reported that sex hormones such as $17 \beta$-estradiol (E2), T, and dehydroepiandrosterone (DHT) exert an effect on PPAR $\gamma$ expression in insulin-target tissues such as liver, muscle, and fat. ${ }^{16-19)}$ Therefore, sex hormones and their receptors clearly play a role in adipose regulation via $\operatorname{PPAR} \gamma$. However, the effects induced by sex hormones appear 
to vary depending on conditions such as the tissues being investigated, treatment periods, and differentiation status. In addition, results from such studies often remain controversial. In this study, to help elucidate the mechanism underlying the gender-related differences of pioglitazone, we concentrated on the major target cells of this drug, adipocytes, and investigated the effects of sex hormones on PPAR $\gamma$ expression and function under several conditions.

\section{MATERIALS AND METHODS}

Reagents All cultures and reagents were purchased from Sigma (St. Louis, MO, U.S.A.), unless otherwise indicated. A representative PPAR $\gamma$ agonist, pioglitazone, was obtained from Takeda Pharmaceuticals Inc. (Osaka, Japan) and dissolved in dimethyl sulfoxide (DMSO). E2 was also dissolved in DMSO, whereas $\mathrm{T}$ and $5 \alpha$-androstan-17 $\beta$-ol-3-one (dihydrotestosterone; DHT) were dissolved in ethanol. The final DMSO or ethanol volumes were kept under $0.1 \%$. The enzyme-linked immunosorbent assay (ELISA) kit for mouse adiponectin was obtained from R\&D systems (Minneapolis, MN, U.S.A.). Information on the antibodies used is provided in the Western blotting analysis section below.

Cell Lines and Culture Conditions 3T3-L1 cells (Health Sciences Research Resources Bank, No. JCRB9014, Osaka, Japan), which are commonly used mouse preadipocytes, were maintained in Dulbecco's modified Eagle's medium (DMEM) according to a published method. ${ }^{20)}$ Briefly, $5 \times 10^{5}$ cells/well of 3T3-L1 were seeded in 6-well plates. After the cells reached confluent status, differentiation was induced with an "induction medium," which contained 10\% fetal bovine serum (FBS; Equitech Bio Inc., Kerrville, TX, U.S.A.), 1.0 units $/ \mathrm{mL}$ penicillin (Gibco BRL, Grand Island, NY, U.S.A.), $2.0 \mathrm{mg} / \mathrm{mL}$ streptomycin (Gibco BRL), $0.25 \mu \mathrm{M}$ dexamethasone (Dex), $0.5 \mathrm{~mm}$ 3-isobutyl-1-methylxanthine (IBMX), and $10 \mu \mathrm{g} / \mathrm{mL}$ insulin, in an atmosphere at $37^{\circ} \mathrm{C}$ with $5 \% \mathrm{CO}_{2}$ (day 0 ). Next, the cell culture medium was changed to "maturation medium," which contained $5 \mu \mathrm{g} / \mathrm{mL}$ insulin in addition to FBS and antibiotics (day 2). After an additional $48 \mathrm{~h}$, the cell culture medium was finally changed to DMEM containing only FBS and antibiotics (day 4); this condition was then maintained until day 14. The culture medium was changed every $2-3 \mathrm{~d}$. With this protocol, more than $90 \%$ adipocyte differentiation was achieved, as indicated by the typical appearance of adipocytes on day 14 . On day 14, the 3 sex hormones (E2, T, or DHT) and pioglitazone were added depending on the mono-treatment or co-treatment conditions for the indicated time period in each assay.

Oil-Red O Staining For Oil-red O staining, the cultured cells were fixed on plates with $10 \%$ formalin neutral buffer solution for $10 \mathrm{~min}$, and rinsed 3 times with phosphate buffered saline (PBS). The fixed cells were stained with Oil-red $\mathrm{O}$ staining solution $(0.3 \%$ Oil-red $\mathrm{O}$ in 2-propanol, diluted $3: 2$ in water, and then filtered with a $0.22-\mu \mathrm{m}$ filter just before staining) for $1 \mathrm{~h}$ at room temperature. The cells were rinsed 2 times with PBS and air-dried before visualization and documentation using a microscope.

Western Blotting Analysis Anti-PPAR $\gamma$ antibody, sc-7196; donkey anti-rabbit immunoglobulin G (IgG) HRP, sc-2313; goat anti-mouse IgG HRP, sc-2005; and U-937 cell lysate were purchased from Santa Cruz Biotechnology, Inc. (CA, U.S.A.). Monoclonal anti- $\beta$-actin (clone AC-74 mouse ascites fluid) was purchased from Sigma. Cells were collected by scraping and then dissolved in ice-cold RIPA buffer $(50 \mathrm{~mm}$ Tris- $\mathrm{HCl}$ ( $\mathrm{pH} 8.0$ ), $150 \mathrm{~mm} \mathrm{NaCl}, 0.2 \mathrm{~mm}$ phenylmethanesulfonyl fluoride (PMSF) solution, $0.1 \%$ sodium dodecyl sulfate (SDS; Wako), $2 \mathrm{~mm}$ ethylenediaminetetraacetic acid (EDTA), $1 \%$ Triton X-100, and $1 \%$ protease inhibitor cocktail). Each sample, which included $25 \mu \mathrm{g}$ of protein, was electrophoresed through a $5 \%$ or $10 \%$ SDS-polyacrylamide (Wako) gel and transferred to a polyvinylidene difluoride (PVDF) membrane (ATTO Corp., Tokyo, Japan). The membranes were blocked with Ezblock (ATTO) and then subjected to immunoblotting with each polyclonal antibody for $\operatorname{PPAR} \gamma(1: 400), \beta$-actin $(1: 5000)$, goat anti-mouse IgG-HRP $(1: 7500)$, and donkey anti-rabbit IgG-HRP $(1: 7500)$. The antibodies were diluted with $0.1 \%$ BSA- $-0.5 \%$ FBS in TBS-T for PPAR $\gamma$, and $0.1 \%$ skim milk for $\beta$-actin and mouse IgG. Detection was accomplished using Immobilon Western Chemiluminescent HRP Substrate (Millipore, Tokyo, Japan) and a LAS-1000 Plus Luminescent Image Analyzer (FUJIFILM, Tokyo, Japan). Protein bands were measured using Scion Image software (Scion; http:// www.scioncorp.com). Each protein density value was normalized to that of $\beta$-actin.

Isolation of Total RNA and Reverse Transcription (RT)Real Time Polymerase Chain Reaction (PCR) Total RNA was isolated using the RNeasy Mini $\mathrm{Kit}^{\circledR}$ (Qiagen, Valencia, CA, U.S.A.) according to the manufacturer's instructions. cDNA was synthesized in a $20-\mu \mathrm{L}$ reaction mixture with $1 \mu \mathrm{g}$ of total RNA using the PrimeScript RT reagent Kit (TaKaRa Bio Inc., Shiga, Japan). Conventional RT-PCR was performed using Takara Thermal Cycler, and Real-time PCR was performed using the ABI StepOne Real Time PCR System (Applied Biosystems Japan Ltd., Tokyo, Japan) with SYBR Premix Ex Taq (TaKaRa Bio Inc.). The primer sequences for $\operatorname{PPAR} \gamma$, adiponectin, and $\beta$-actin are listed in Table 1 . Conventional RT-PCR for PPAR $\gamma$ and $\beta$-actin were performed at $95^{\circ} \mathrm{C}$ for $2 \mathrm{~min}$, followed by 25 cycles at $95^{\circ} \mathrm{C}$ for $30 \mathrm{~s}, 58^{\circ} \mathrm{C}$ for $30 \mathrm{~s}$, and $72^{\circ} \mathrm{C}$ for $30 \mathrm{~s}$, then $72^{\circ} \mathrm{C}$ for $5 \mathrm{~min}$. All of Real-time PCR was performed at $95^{\circ} \mathrm{C}$ for $10 \mathrm{~s}$, followed by 40 cycles at $95^{\circ} \mathrm{C}$ for $5 \mathrm{~s}$ and $60^{\circ} \mathrm{C}$ for $31 \mathrm{~s}$. All data were normalized to the $\beta$-actin values, which served as an internal standard.

ELISA System for Adiponectin Secretion and Real-Time PCR for Adiponectin mRNA 3T3-L1 adipocytes were obtained as described in the "Cell lines and culture conditions" section above. On day 7, cells were stimulated with E2,

Table 1. Primer Sequences Used for RT-PCR

\begin{tabular}{|c|c|c|}
\hline Gene & Primer sequence $\left(5^{\prime} \rightarrow 3^{\prime}\right)$ & $\begin{array}{l}\text { Product } \\
\text { size } \\
\text { (bp) }\end{array}$ \\
\hline PPAR $\gamma 2$ & $\begin{array}{l}\text { F: GCT GTT ATG GGT GAA ACT CTG } \\
\text { R: ATA AGG TGG AGA TGC AGG TTC }\end{array}$ & 352 \\
\hline$\beta$-Actin-1 & $\begin{array}{l}\text { F: AGT AAG ATC CTG ACC GAG CGT G } \\
\text { R: CTT GCT GAT CCA CAT CTG CTG G }\end{array}$ & 510 \\
\hline$\beta$-Actin-2 & $\begin{array}{l}\text { F: TGT CCA CCT TCC AGC AGA TGT } \\
\text { R: AGC TCA GTA ACA GTC CGC CTA GA }\end{array}$ & 101 \\
\hline Adiponectin & $\begin{array}{l}\text { F: TCC TGG AGA GAA GGG AGA GAA } \\
\text { AG } \\
\text { R: TCA GCT CCT GTC ATT CCA ACA T }\end{array}$ & 85 \\
\hline
\end{tabular}

$\mathrm{F}$ : forward primer, R: reverse primer, PPAR $\gamma 2$ : primers for both conventional and real-time PCR, $\beta$-actin-1: primers for conventional RT-PCR, $\beta$-actin- 2 and adiponectin: primers for real-time RT-PCR 

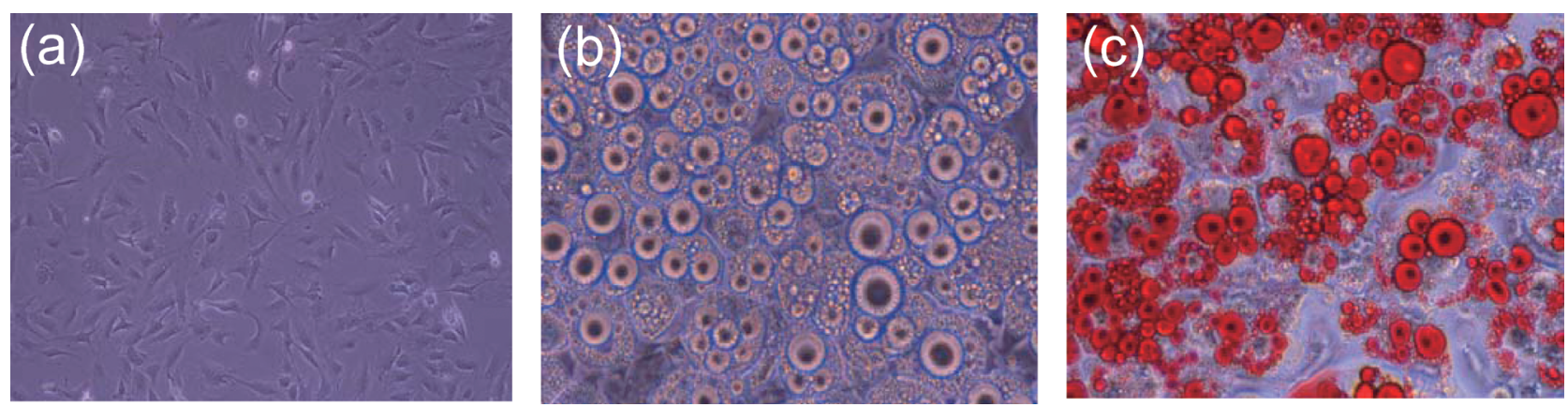

Fig. 1. Differentiation of 3T3-L1 Preadipocytes into Adipocytes

Microphotographs were obtained on days 0 (a) and 14 (b). Oil-red O staining was performed on day 14 (c) to identify lipid droplet formation (magnification, $\times 40$ ).

T, DHT, or pioglitazone under serum-free conditions. After $12 \mathrm{~h}$ of treatment, the cell culture medium was collected for ELISA, and also cells were collected for detection of adiponectin mRNA using real-time PCR method. ELISA was then performed according to the manufacturer's protocol to detect adiponectin secretion from the 3T3-L1 adipocytes. Real-time PCR was performed as described in "Isolation of total RNA and RT-real time PCR" section above.

Luciferase Assay for PPAR $\gamma$ Transcriptional Activity To examine whether sex hormones could affect on PPAR $\gamma$ transcriptional activity, reporter assay was performed with PPRE-luciferase vector. In this study, MCF-7 (human breast cancer cell) was used because multiple reports have shown it is well-established model so far. ${ }^{21-23)} \mathrm{MCF}-7$ cells (Cell bank of Health Sciences Research Resources Bank, No. JCRB0134) were maintained in RPMI-1640 containing 10\% FBS and antibiotics. The mouse (PPRE $\times 3)$-t $k$-luciferase expression vector $(\mathrm{PPRE} \times 3)$ was purchased from Addgene (Cambridge, MA, U.S.A.), and the Rluc gene expression vector (pRL-SV40) was kindly provided by Dr. Nishimura K (Chiba University, Japan) and served as an internal standard. Cells were plated in 12well plates at a concentration of $2.5 \times 10^{5}$ cells per well. The following day, cells were transfected with PPRE $\times 3$ and $\mathrm{pRL}-$ SV40 (4:2) using Fugene HD transfection reagent (Roche Applied Sciences, Tokyo, Japan) according to the manufacturer's instructions. Then, sex hormones, pioglitazone, or combination of hormones and pioglitazone were added $24 \mathrm{~h}$ after transfection. The cells were harvested after $24 \mathrm{~h}$ of incubation and then lysed in the recommended lysis buffer for luciferase (Promega, Tokyo, Japan). The luciferase activity was determined using Luminometer Version 1.12 (Turner Designs, Sunnyvale, CA, U.S.A.)

Statistical Analysis The data were analyzed using oneway analysis of variance, followed by Dunnett's test or the Tukey-Kramer's test. A $p$ value of less than 0.05 was considered significant.

\section{RESULTS}

Treatment with Chronic E2 Upregulated PPAR $y$ Protein Expression Oil-red O staining confirmed that the 3T3-L1 cells reached maturity on day 14 (Fig. 1). Treatment with the sex hormones (E2 or DHT) started on day 14. Neither E2 nor DHT showed any specific effects on PPAR $\gamma$ expression after short-term (24-72h) treatment (Figs. 2a,b). In contrast, E2 significantly upregulated PPAR $\gamma$ expression after long-term (1 week or 2 weeks) treatment in a time- and concentration-
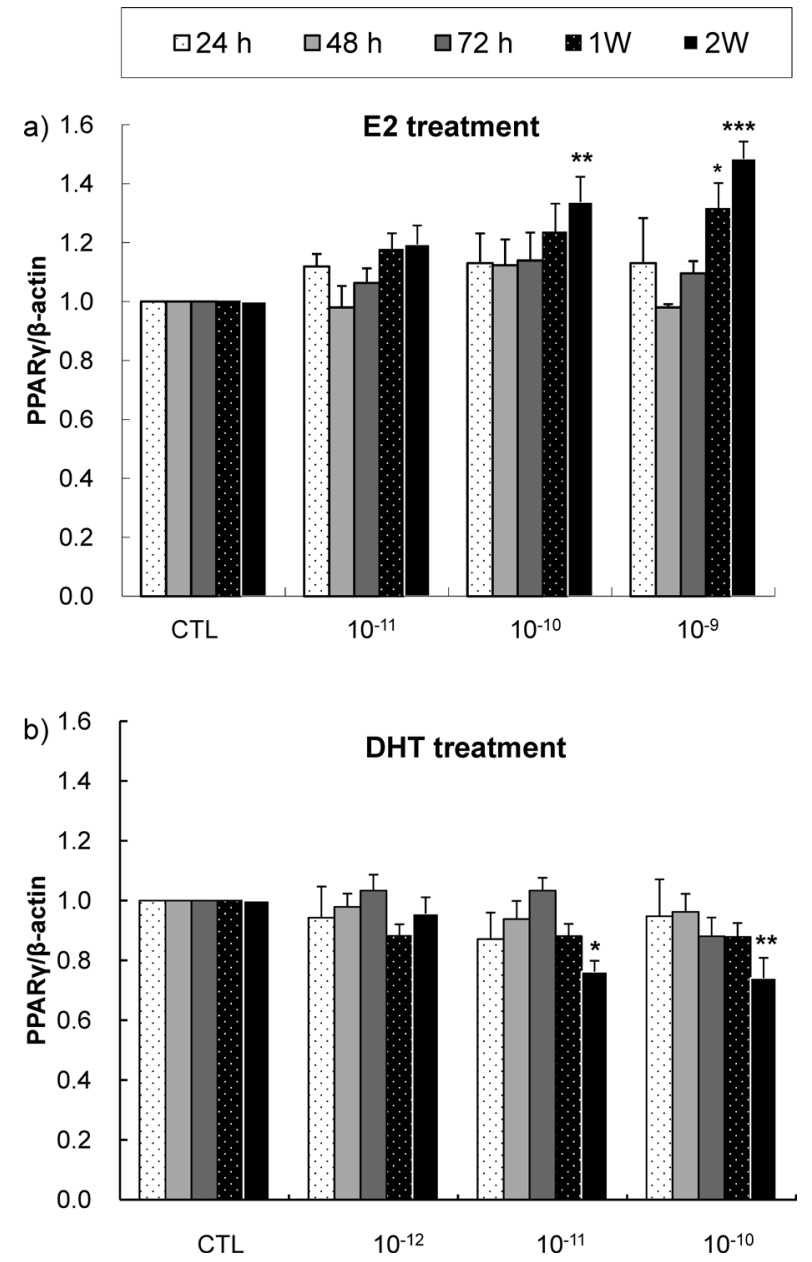

Fig. 2. Effect of (a) $17 \beta$-Estradiol (E2) or (b) Dihydrotestosterone (DHT) on Peroxisome Proliferator-Activated Receptor (PPAR) $\gamma$ Protein Expression after Short (24h, 48h, and $72 \mathrm{~h}$ ) and Long (1 Week, 2 Weeks) Periods

$\operatorname{PPAR} \gamma$ expression was normalized using $\beta$-actin for each sample. Data shown are expressed as mean \pm S.E.M. of three independent experiments. $* p<0.05$, $* * p<0.01$, and $* * * p<0.001$ indicate significant differences from the control (CTL) for each time point (Dunnett's test).

dependent manner (Fig. 2a), whereas DHT significantly downregulated its expression after the 2-week treatment (Fig. 2b).

PPAR $\gamma$ mRNA Expression Was Not Altered by Treatment with E2 or DHT To examine whether the changes in expression observed at the protein level were associated with altered mRNA expression, the level of PPAR $\gamma$ mRNA was 
a)

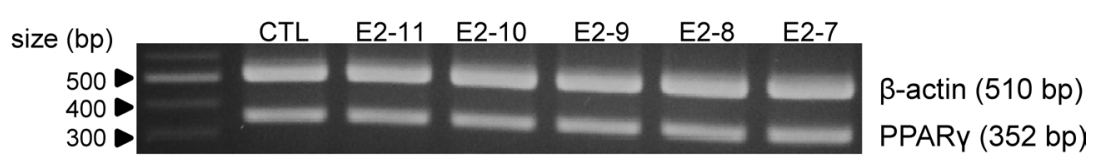

b)

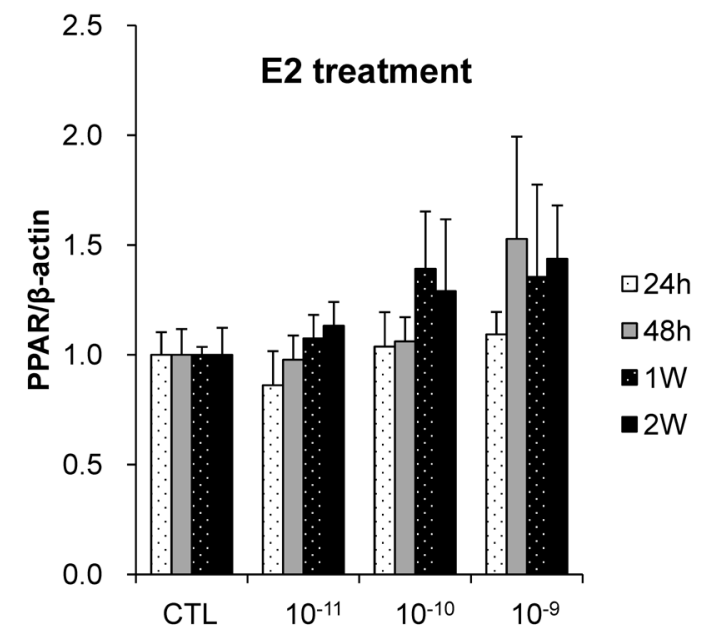

c)

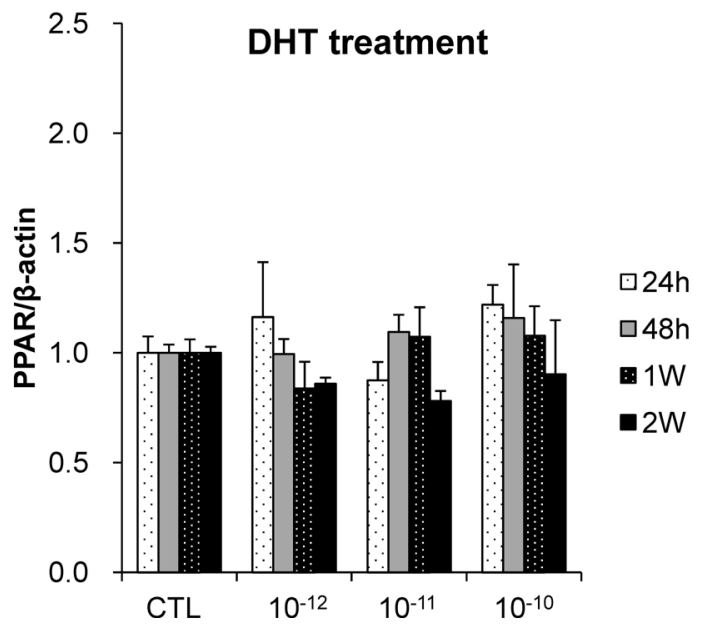

Fig. 3. Peroxisome Proliferator-Activated Receptor (PPAR) $\gamma$ mRNA Expression after 17 $\beta$-Estradiol (E2) or Dihydrotestosterone (DHT) Treatment for $24 \mathrm{~h}, 48 \mathrm{~h}, 1$ Week $(1 \mathrm{~W})$, or 2 Weeks $(2 \mathrm{~W})$

(a) shows a representative photo of PCR products which were electrophoresed after conventional PCR (25 cycles). After real-time PCR, PPAR $\gamma$ expression levels were divided by the values obtained for $\beta$-actin expression, and then normalized to each control (CTL). RNA were extracted from cells after treatment with E2 (b) or DHT (c). Data shown are expressed as mean \pm S.E.M. of three independent experiments. Cells were treated with indicated concentrations of compounds, respectively.

quantified in 3T3-L1 cells that were treated with E2 or DHT and isolated at each time point. At first, primer efficacy was checked by conventional RT-PCR to get single band (Fig. 3a), then real time RT-PCR was performed for quantification. The results obtained differed from the protein patterns observed, with PPAR $\gamma$ mRNA expression not showing any significant change after treatment with either E2 or DHT, though it seemed to be upregulated by E2 and be decreased by DHT at higher concentrations, for a long period-exposure (Figs. 3b, c).

E2 Shifted the PPAR $\gamma$ Protein Expression Which Was Downregulated by Pioglitazone Next, we examined if the co-culture of sex hormones and pioglitazone would induce a different effect on PPAR $\gamma$ protein expression compared with that observed under monoculture. After 2 weeks of treatment, pioglitazone monoculture showed a significant downregula- tion of PPAR $\gamma$ protein expression (Fig. 4i). This trend was also observed when the cells were co-cultured with DHT and pioglitazone (Fig. 4iib). However, expression was significantly upregulated when the cells were co-cultured with E2 and pioglitazone (Fig. 4iia), similar to the pattern observed for E2 monoculture (Fig. 2a).

Adiponectin Secretion Was Downregulated by DHT Adiponectin secretion is thought to confirm the matured phenotype of adipocytes and plays a significant role in insulinresponsive metabolism in a physiological environment. In addition, adiponectin secretion is one of the major factors regulated by PPAR $\gamma$. To examine whether sex hormones have an effect on adiponectin secretion, the cell culture medium was collected and used for ELISA. The adiponectin level increased consistently with the differentiation periods, reaching a maxi- 


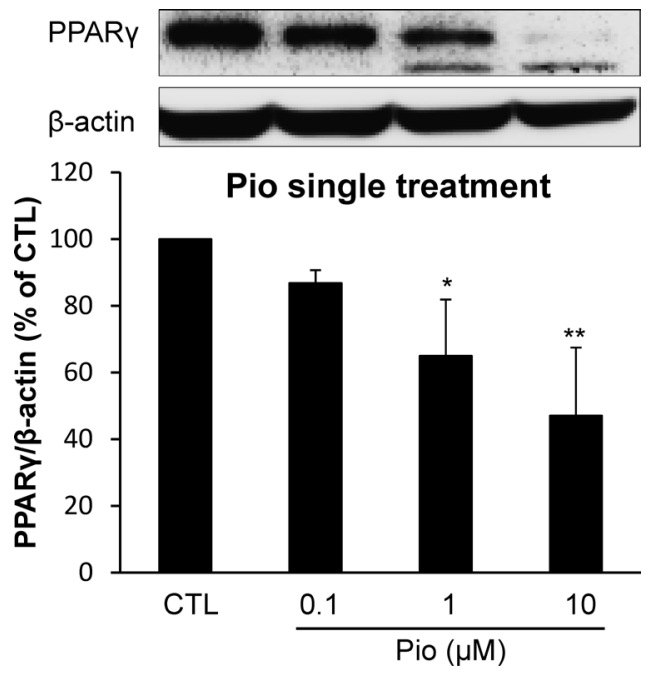

Fig. 4-i. Effect of Pioglitazone (Pio) on Peroxisome Proliferator-Activated Receptor (PPAR) $\gamma$ Protein Expression in 3T3-L1 Adipocytes

Cells were treated with Pio at the indicated concentrations for 2 weeks. $\beta$-Actin was used as an internal standard. Relative PPAR $\gamma$ expression levels were normalized to the control (CTL). The photo in the upper panel shows representative data. The columns shown are expressed as mean \pm S.E.M. of three independent experiments. $* p<0.05, * * p<0.01$ indicate significant differences from the CTL (Dunnett's test).

mum on day 12, then gradually decreased (Fig. 5i). The sex hormones were added to the cells on day 7, when adiponectin secretion was in an increasing phase. After $24 \mathrm{~h}$, the cell culture medium was collected and ELISA was performed. As expected, adiponectin secretion after treatment with pioglitazone showed an increasing trend (Fig. 5iia). On the other hand, E2 had no effect (Fig. 5iib). In contrast, the secretion after treatment with DHT and T showed decreasing trends (Fig. 5iic, d). In particular, treatment with $10^{-8} \mathrm{M}$ of DHT resulted in a significant change. Moreover, adiponectin mRNA was simultaneously detected by real time RT-PCR. Both single treatment of E2 and DHT seemed to decrease adiponectin mRNA level, however, co-treatment with sex hormones and pioglitazone revealed to show that there was an increasing trend in E2 with pioglitazone, whereas a decreasing trend in case of DHT (Fig. 5iii). This result suggests that the regulation of adiponectin secretion by sex hormones might be partly modified at transcriptional level.

Co-treatment with E2 and Pioglitazone Upregulated PPAR $y$ Transcriptional Activity Finally, to determine the mechanisms by which sex hormones affect PPAR $\gamma$ expression, MCF-7 cells were transiently transfected with a luciferase reporter gene construct (PPREx3-tk-luc; PPRE). As expected, pioglitazone elevated the luciferase reporter activity to a greater extent than that observed in control sample which was transfected with PPRE and without any drug treatment (Fig. 6). In contrast, single treatment with sex hormones did not change reporter activity. On the other hand, co-treatment with DHT and pioglitazone significantly downregulated the activity compared with pioglitazone alone, whereas E2 also seemed to decrease the activity but was not significant change.

\section{DISCUSSION}

The present study demonstrates that the expression and function of PPAR $\gamma$ may be altered after treatment with physi- a)
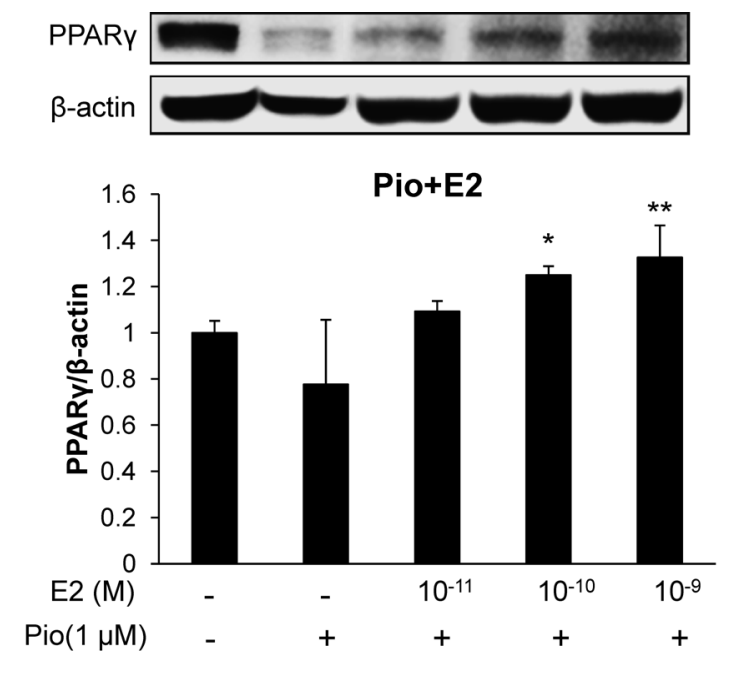

b)
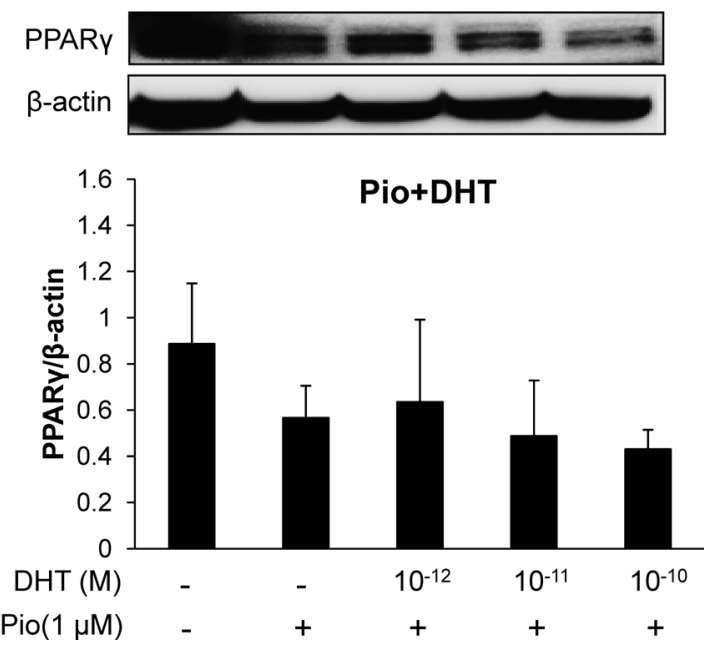

Fig. 4-ii. Effect of Co-treatment with Pioglitazone (Pio) and Sex Hormones (17 $\beta$-Estradiol [E2] or Dihydrotestosterone [DHT]) on Peroxisome Proliferator-Activated Receptor (PPAR) $\gamma$ Protein Expression in 3T3-L1 Adipocytes

Cells were treated with Pio $(1 \mu \mathrm{M})$ and (a) E2 or (b) DHT at the indicated concentrations for 2 weeks. $\beta$-Actin was used as an internal standard. Relative $\operatorname{PPAR} \gamma$ expression levels were normalized to the control (CTL). Each photo in the upper panel shows representative data. The columns shown are expressed as mean \pm S.E.M. of three independent experiments. ${ }^{*} p<0.05, * * p<0.01$ indicate significant differences from each CTL (Dunnett's test).

ological concentrations of sex hormones for a long period with or without exposure to pioglitazone. Furthermore, we have shown that the main difference between the actions of E2 and androgen (DHT or T) involves their effect on PPAR $\gamma$ expression at the protein level.

Wada et al. suggested that there are many controversial reports regarding E2 that may be due to the different experimental conditions used in various studies. ${ }^{24)}$ Some reports exclusively used higher concentrations of sex hormones compared with those present in a biological environment, ${ }^{25}$ ) where estrogen concentrations range from $10-80 \mathrm{pg} / \mathrm{mL}$ in the follicular phase, $50-350 \mathrm{pg} / \mathrm{mL}$ in the ovulation phase, and $30-150 \mathrm{pg} / \mathrm{mL}$ in the luteal phase, which represents $10^{-11}$ to $10^{-9} \mathrm{M}$ of E2. During pregnancy, the concentration of E2 


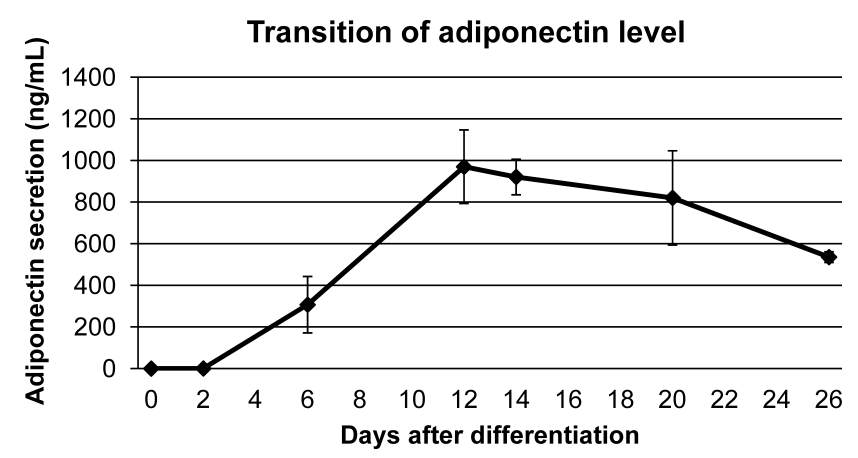

Fig. 5-i. Adiponectin Secretion from 3T3-L1 Cells during the Differentiation Period

Data are shown as mean \pm S.E.M. of at least three independent experiments.

increases to $1800-61000 \mathrm{pg} / \mathrm{mL}$, which is 100 - to 10000 -fold higher than the usual concentration. In contrast, the total androgen concentration in plasma is $247-836 \mathrm{ng} / \mathrm{dL}$ in males and $10-60 \mathrm{ng} / \mathrm{dL}$ in females, whereas free $\mathrm{T}$ concentration is $8.5-27.9 \mathrm{pg} / \mathrm{mL}$ in males and less than $2.7 \mathrm{pg} / \mathrm{mL}$ in females, which represents $10^{-11}$ to $10^{-10} \mathrm{M}$ of $\mathrm{T}$. Therefore, the concentrations of sex hormones used in this study were almost equal to those present in the biological environment.

In this study, we focused on adipocytes as pioglitazone target cells because preadipocytes and adipocytes have also been shown to be target cells for sex hormones. Dieudonne et al. found that exposure to estrogen increased the proliferation rate of subcutaneous adipocytes isolated from female rats only, but not from those of males. ${ }^{26}$ Additionally, the authors demonstrated that $\mathrm{T}$ acted as a negative effector of rat preadipocyte terminal differentiation and suggested that the mechanism underlying these responses involved the regulation of genes encoding adipogenic transcriptional factors. Among these factors, PPAR $\gamma 2$ was considered as one of the master regulator genes of the adipoconversion process. The authors showed that PPAR $\gamma 2$ expression was increased after estrogen exposure in epididymal adipocytes from male rats and in parametrial adipocytes from ovariectomized rats, whereas $\mathrm{T}$ levels slightly decreased the expression of PPAR $\gamma 2$ in epididymal adipocytes. Our previous report showing that the expression of PPAR $\gamma 2$ in perigonadal adipose tissues was significantly higher in females than in males, and that PPAR $\gamma 2$ levels in perigonadal adipose tissues in females significantly decreased during diestrus, appears to be consistent with the results of Dieudonne et al. ${ }^{8)}$ Taken together, the effects of sex hormones against PPAR $\gamma 2$ may play a crucial role in the effect of pioglitazone on adipose tissue, although we were unable to distinguish between PPAR $\gamma 1$ and PPAR $\gamma 2$ in the present study.

As expected, the present study revealed that a longer period of exposure to E2 significantly increased PPAR $\gamma$ protein expression, whereas DHT exposure significantly decreased its expression. However, PPAR $\gamma$ expression at the mRNA level was not significantly affected by sex hormones. Several possible mechanisms have been reported which may help explain this discrepancy. The stability of mRNA and posttranslational modifications (PTMs) are important factors; for example, the androgen receptor (AR), a famous nuclear receptor as PPAR $\gamma$, is known to undergo unique posttranscriptional events. Yeap et al. demonstrated that DHT (one of AR ligands) regulates AR mRNA transcription and mRNA turnover leading to a net
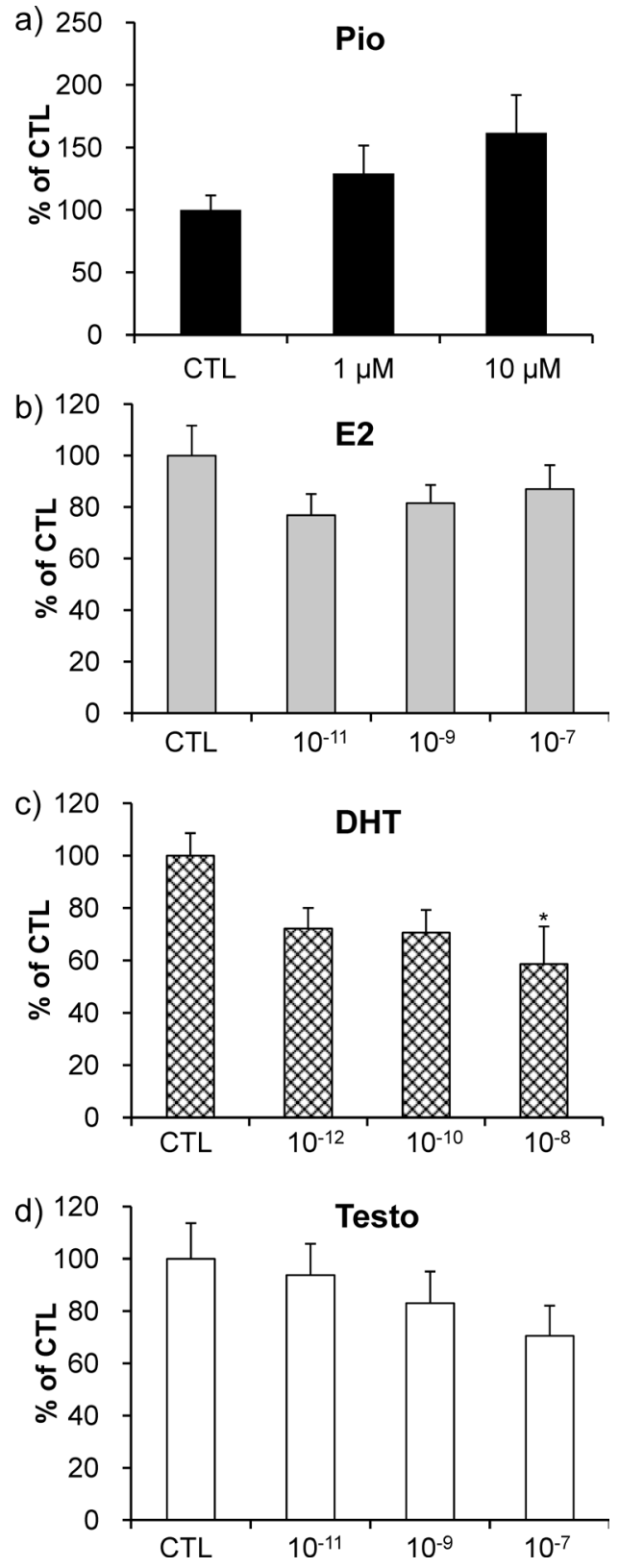

Fig. 5-ii. Adiponectin Secretion from 3T3-L1 Cells on Day 8 after 24-h Treatment with Sex Hormones or Pioglitazone

Samples treated with (a) pioglitazone (Pio), (b) 17 $\beta$-estradiol (E2), (c) dihydrotestosterone (DHT), and (d) testosterone (Testo) were normalized to the control (CTL). Cells were treated with indicated concentrations of compounds, respectively. The columns shown are expressed as mean \pm S.E.M. of three independent experiments. ${ }^{*} p<0.05$ indicates significant differences from the CTL (Dunnett's test).

decrease in AR mRNA, accompanied by increased AR protein expression and cellular proliferation in $\mathrm{LNCaP}$ prostate cancer cells (androgen-responsive). In contrast, in MDA453 breast cancer cells (AR positive), DHT had no effect on AR transcription, whereas an opposite effect was induced on AR mRNA turnover and cellular proliferation, despite producing a similar increase in AR protein expression. A possible mechanism was explained in their report from the aspect of fundamentally different system underlying AR mRNA autoregulation by DHT in LNCaP and MDA453 cells; In LNCaP cells, the downregulation of AR mRNA by DHT occurs at the transcriptional level, but in MDA453 cells, the downregulation of AR mRNA resulted primarily from the posttranscriptional 

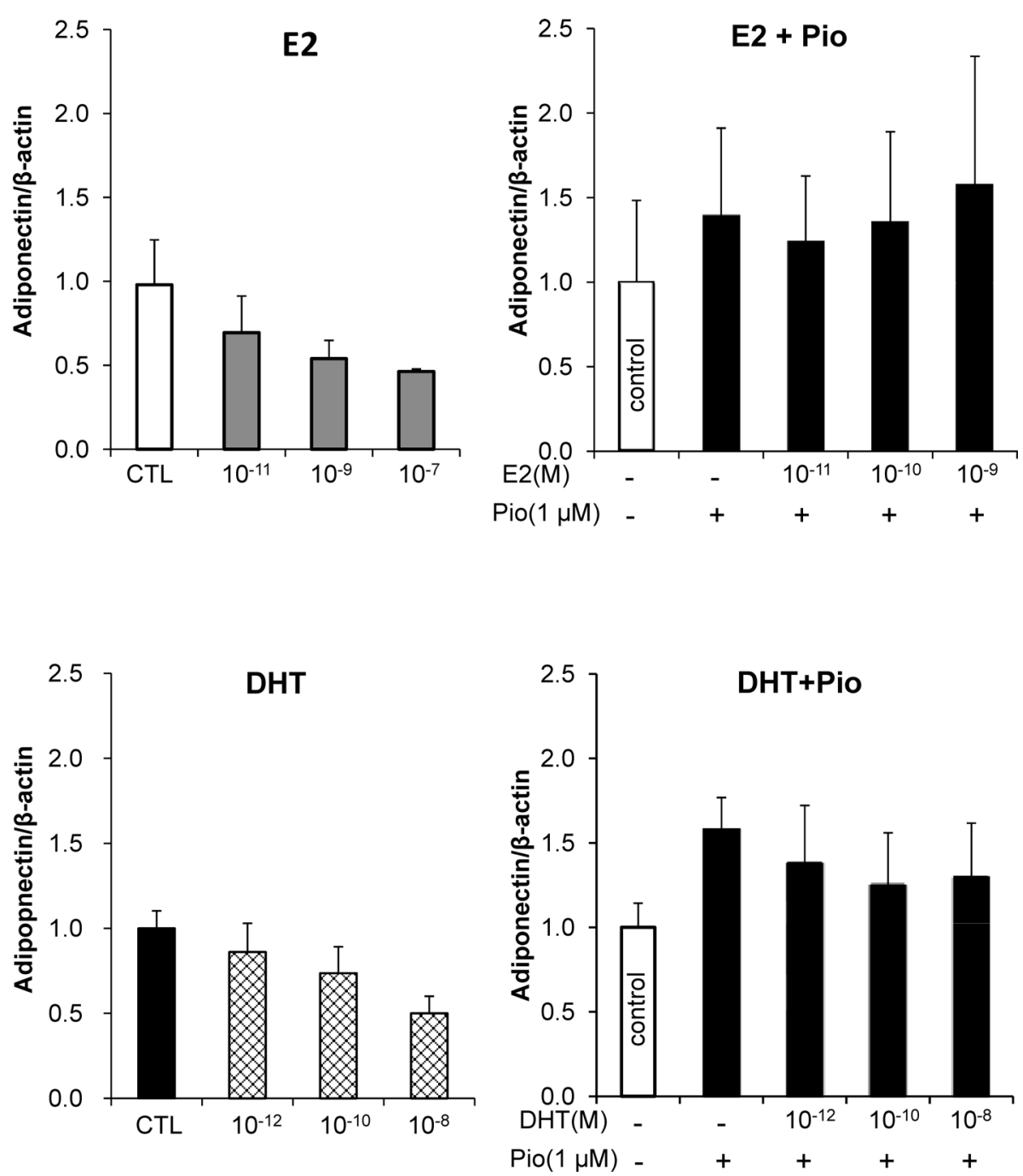

Fig. 5-iii. Adiponectin mRNA Expression on Day 8 after 24-h Treatment with Only Sex Hormones, or 24-h Co-treatment with Pioglitazone (Pio) and Sex Hormones (17 $\beta$-Estradiol [E2] or Dihydrotestosterone [DHT])

Cells were treated with indicated concentrations of compounds, respectively. The columns shown are expressed as mean \pm S.E.M. of at least three independent experiments.

destabilization of AR mRNA. ${ }^{27)}$ Therefore, in present study, regulation of PPAR $\gamma$ expression by sex hormones at the protein level could be speculated to involve not only transcriptional modification, but posttranscriptional mechanisms as well.

In fact, some PPAR $\gamma 1$ regulation mechanisms have been suggested. Multiple PPAR $\gamma 1$ transcript variants (PPAR $\gamma-1,-3$, and -4), all of which encode for the same protein (PPAR $\gamma 1$ ), has been reported to involve the mRNA stability. ${ }^{28)}$ Another evidence was also provided that microRNA-27a/b, which is induced in macrophages upon exposure to lipopolysaccharide, contributes to the destabilization of PPAR $\gamma 1$ mRNA during chronic inflammatory diseases. ${ }^{29)}$ Although there are multiple reports on the mechanisms regulating PPAR $\gamma 1$ expression, less is known about the PPAR $\gamma 2$ protein, which is derived only from the PPAR $\gamma 2$ transcript variant. Taken together, further detailed studies are needed to provide a better understanding of the regulation of PPAR $\gamma 2$ in adipocytes.

On another front, PPAR $\gamma$ and the sex hormone receptors, particularly the estrogen receptor (ER), are members of the well-known and well-studied nuclear hormone receptor superfamily of ligand-activated transcription factors, and therefore, share similar cofactors. Several studies have suggested that a mutual signaling cross-talk exists between the ERs and PPAR $\%$. Jeong and Yoon showed that estrogen inhibits adipogenesis induced by troglitazone, another PPAR $\gamma$ agonist, via suppression of PPAR $\gamma$ and PPAR $\gamma$ target genes. ${ }^{30)}$ The authors suggested that the suppressive effect of estrogen might result from the interaction of CREB-binding protein (CBP), which is a common coactivator, with ER, thereby preventing the binding of PPAR $\gamma$ to CBP. Moreover, it could be speculated that under certain conditions, PPAR $\gamma$ and ER may work as synergetic inducers to their targets genes and vice versa. Our result from PPRE reporter gene assay revealed that cotreatment with E2 and pioglitazone showed mildly decrease the reporter activity compared with pioglitazone alone but it was not significant change. Also it was not significantly different from basal control level (no-treatment sample). It might be partly affected by PPAR $\gamma$ and ER cross-talk but totally it could be more like that E2 dose not reduce pioglitazone induced reporter activity. On the other hand, it has also been reported that cross-talk may occur between PPAR $\gamma$ and the AR via their common coactivator ARA70, which was originally described as a coactivator of the AR. ${ }^{31)}$ Addition- 


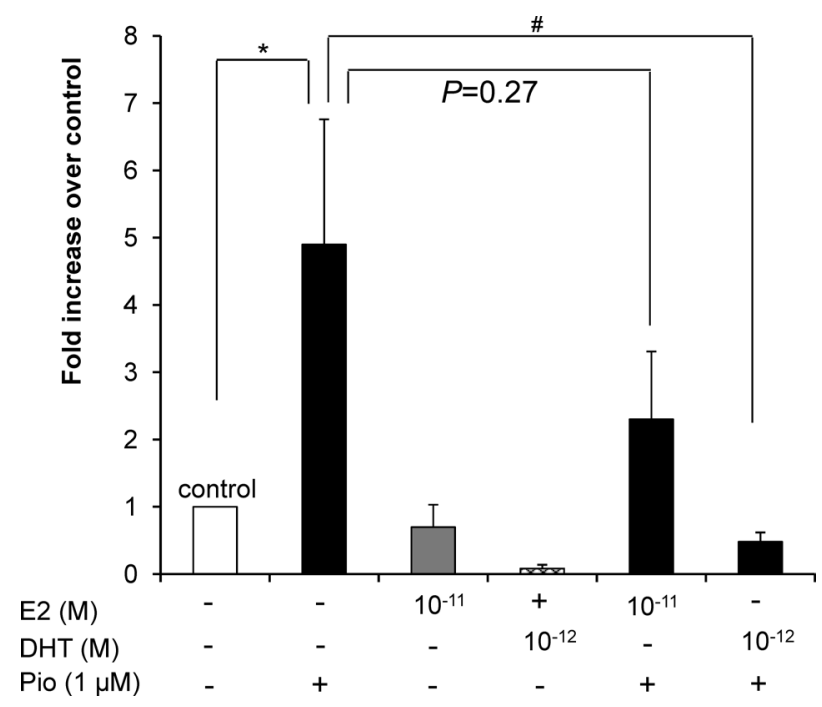

Fig. 6. Luciferase Assay of a Reporter Gene Demonstrating the Effect of Pioglitazone (Pio) and Sex Hormones on Peroxisome ProliferatorActivated Receptor (PPAR) $\gamma$ Activation in MCF-7 Cells

Cells were transiently transfected with reporter plasmid PPRE-tk-Luc and treated with (a) pioglitazone, (b) $17 \beta$-estradiol (E2), or (c) dihydrotestosterone (DHT) for $24 \mathrm{~h}$. Luciferase activities were normalized to control (cells which were transfected with PPRE-tk-Luc, but were non-treated with any drugs). The columns shown are expressed as mean \pm S.E.M. of at least three independent experiments. ${ }^{*} p<0.05$, ${ }^{\#} p<0.05$, which mean significant differences between each of the indicated groups (Tukey-Kramer's test).

ally, Singh et al. reported the intracellular events triggered by androgen binding to AR are cross-communicated to the Wnt signaling pathway through the association of AR with $\beta$-catenin and translocation of this complex to the cell nucleus, which results in downstream activation of TCF4/LEF and inhibition of adipogenesis. ${ }^{32)}$ Indeed our result showed that cotreatment with DHT and pioglitazone significantly decreased the reporter activity. To investigate whether such molecular interactions between nuclear hormone receptors involve to adipogenic differentiation induced by pioglitazone, agonistic and antagonistic procedure for each receptors should be performed as next step. Be that as it may, this study shows the possibility that sex hormones actually affect on pioglitazone stimulated-PPAR $\gamma$ transcriptional activity.

We demonstrated that pioglitazone downregulated PPAR $\gamma$ protein expression in matured 3T3-L1 cells. Previous reports support our results that thiazolidinediones (TZDs) reduce the mRNA or protein expression of PPAR $\gamma$, although TZDs have been shown to induce the activation of PPAR $\gamma$ via PPREs in matured adipocytes. ${ }^{33-35)}$ Although the mechanism underlying the downregulation of PPAR $\gamma$ protein by TZDs remains unknown, there may be some negative feedback mechanisms involved in the promoter region of PPAR $\gamma$. Recently, PTMs such as phosphorylation status have been reported to be important regulatory systems for PPAR $\gamma$ activities and interactions with coregulators, and/or vice versa, ultimately controlling the transcriptional output of this nuclear receptor. ${ }^{36)}$ It is still unknown whether the increase of PPAR $\gamma$ protein expression by E2 in present study has resulted in the upregulation of PPAR $\gamma$ activity when co-treated with E2 and pioglitazone, however, this phenomenon might contribute to pharmacological activity of pioglitazone. In future studies, the effect of sex hormones on the PTMs of PPAR $\gamma$ should also be investigated to explore another possible level on which sex hormones may have different actions.

It is well-known that pioglitazone increases the secretion of adiponectin, ${ }^{37)}$ as observed in the present study. Additionally, accumulation of lipid storage was increased in matured 3T3-L1 cells by pioglitazone (data not shown). It suggests that differentiation rate might be upregulated by pioglitazone which helps to induce adiponectin secretion. E2 did not affect adiponectin secretion, whereas DHT significantly decreased it. Previous reports demonstrated that the plasma concentration of the high molecular weight (HMW) form of adiponectin is lower in men than in women, but that it is not different between pre- and postmenopausal women, indicating that E2 does not affect adiponectin secretion levels. ${ }^{38)}$ In contrast, $\mathrm{Xu}$ et al. reported that $\mathrm{T}$ selectively impedes the secretion of HMW adiponectin. ${ }^{39)}$ These reports support our findings. This inhibitory effect of $\mathrm{T}$ may contribute to the sexual dimorphism of adiponectin expression and could in part explain why men have a higher risk of insulin resistance and are less sensitive to pioglitazone. Although E2 seemed to have a protective effect on PPAR $\gamma$ protein expression, it was not found to involve adiponectin secretion, which appears to be regulated by PPAR $\gamma$ directly thus far. In addition to E2, there are other possible nuclear orphan receptors that may enhance the transcription of adiponectin in adipocytes, including liver receptor homologue-1 (LRH-1), ${ }^{40)}$ which is known to be affected by sex hormones. ${ }^{41)}$ Therefore, further investigations to identify nuclear receptors candidates that are affected by sex hormones may provide greater clarity. Moreover, it is necessary to carefully keep track of correlation analysis for the effects on the expression and function of the targeted genes and changed phenotypes induced by sex hormones, such as lipogenesis, fatty acid release, and fat storage process where specific action of sex hormones have been suggested. ${ }^{42,43)}$

In conclusion, using physiological levels of sex hormones, E2 is found to potentiate PPAR $\gamma$ expression, even if pioglitazone had a suppressing effect. Moreover, it is suggested that co-treatment with E2 and pioglitazone activates PPAR $\gamma$ transcriptional activity. These effects may indirectly contribute to the increased secretion of adiponectin and stimulate increasingly more insulin-induced glucose uptake in females. In contrast, an endogenous level of DHT, an active form of androgen, was found to decrease PPAR $\gamma$ expression, which may facilitate the reduction in PPAR $\gamma$ expression induced by pioglitazone. As a result, the secretion of adiponectin could be decreased, which may affect drug efficacy in males. Although the findings from papers reported thus far do not agree on how sex hormones affect PPAR $\gamma$, and while further detailed studies are necessary, our results reveal some of the aspects underlying the cause for sex differences in the effects of pioglitazone.

Acknowledgments The authors thank Dr. Keiko Amano, Visiting Professor of Chiba University for her pro bono review of this manuscript. This work was supported in part by Grantin-Aid for Young Scientists (B) No. 24790529 and Grant-inAid for Scientific Research (C) No. 20590138 from the Japan Society for the Promotion of Sciences (JSPS), Grant-in-Aid from Health and Labour Sciences Research Grant, Special Funds for Education and Research (Development of SPECT probes for Pharmaceutical Innovation) from the Ministry of Education, Culture, Sports, Science and Technology (MEXT) 
of Japan and a Research Grant from The Uehara Memorial Foundation. The funders had no role in the study design, data collection and analysis, decision to publish, or preparation of the manuscript.

\section{REFERENCES}

1) Berger JP, Akiyama TE, Meinke PT. PPARs: therapeutic targets for metabolic disease. Trends Pharmacol. Sci., 26, 244-251 (2005).

2) Forman BM, Tontonoz P, Chen J, Brun RP, Spiegelman BM, Evans RM. 15-Deoxy-delta 12,14-prostaglandin J2 is a ligand for the adipocyte determination factor PPAR gamma. Cell, 83, 803-812 (1995).

3) Kliewer SA, Umesono K, Noonan DJ, Heyman RA, Evans RM. Convergence of 9-cis retinoic acid and peroxisome proliferator signalling pathways through heterodimer formation of their receptors. Nature, 358, 771-774 (1992).

4) Tugwood JD, Issemann I, Anderson RG, Bundell KR, McPheat WL, Green S. The mouse peroxisome proliferator activated receptor recognizes a response element in the $5^{\prime}$ flanking sequence of the rat acyl CoA oxidase gene. EMBO J., 11, 433-439 (1992).

5) Rosen ED, Walkey CJ, Puigserver P, Spiegelman BM. Transcriptional regulation of adipogenesis. Genes Dev., 14, 1293-1307 (2000).

6) Giusti V, Verdumo C, Suter M, Gaillard RC, Burckhardt P, Pralong F. Expression of peroxisome proliferator-activated receptor-gamma1 and peroxisome proliferator-activated receptor-gamma2 in visceral and subcutaneous adipose tissue of obese women. Diabetes, 52 , 1673-1676 (2003).

7) Rodríguez E, Ribot J, Rodríguez AM, Palou A. PPAR-gamma2 expression in response to cafeteria diet: gender- and depot-specific effects. Obes. Res., 12, 1455-1463 (2004).

8) Kadowaki K, Fukino K, Negishi E, Ueno K. Sex differences in PPARgamma expressions in rat adipose tissues. Biol. Pharm. Bull., 30, 818-820 (2007).

9) Tajiri Y, Takei R, Mimura K, Umeda F. Indicators for the efficacy of pioglitazone before and during treatment in Japanese patients with type 2 diabetes. Diabetes Technol. Ther., 9, 429-437 (2007).

10) Fujita Y, Yamada Y, Kusama M, Yamauchi T, Kamon J, Kadowaki T, Iga T. Sex differences in the pharmacokinetics of pioglitazone in rats. Comp. Biochem. Physiol. C Toxicol. Pharmacol., 136, 85-94 (2003).

11) Macotela Y, Boucher J, Tran TT, Kahn CR. Sex and depot differences in adipocyte insulin sensitivity and glucose metabolism. Diabetes, 58, 803-812 (2009).

12) Ley CJ, Lees B, Stevenson JC. Sex- and menopause-associated changes in body-fat distribution. Am. J. Clin. Nutr., 55, 950-954 (1992).

13) Frias JP, Macaraeg GB, Ofrecio J, Yu JG, Olefsky JM, Kruszynska YT. Decreased susceptibility to fatty acid-induced peripheral tissue insulin resistance in women. Diabetes, 50, 1344-1350 (2001).

14) Hevener A, Reichart D, Janez A, Olefsky J. Female rats do not exhibit free fatty acid-induced insulin resistance. Diabetes, 51, 1907-1912 (2002).

15) Soeters MR, Sauerwein HP, Groener JE, Aerts JM, Ackermans MT, Glatz JF, Fliers E, Serlie MJ. Gender-related differences in the metabolic response to fasting. J. Clin. Endocrinol. Metab., 92, 3646-3652 (2007).

16) Lundholm L, Zang H, Hirschberg AL, Gustafsson JA, Arner P, Dahlman-Wright K. Key lipogenic gene expression can be decreased by estrogen in human adipose tissue. Fertil. Steril., 90, 44-48 (2008).

17) Phrakonkham $P$, Viengchareun $S$, Belloir C, Lombès M, Artur Y, Canivenc-Lavier MC. Dietary xenoestrogens differentially impair 3T3-L1 preadipocyte differentiation and persistently affect leptin synthesis. J. Steroid Biochem. Mol. Biol., 110, 95-103 (2008).
18) Nada SE, Thompson RC, Padmanabhan V. Developmental programming: differential effects of prenatal testosterone excess on insulin target tissues. Endocrinology, 151, 5165-5173 (2010).

19) Karbowska J, Kochan Z. Effect of DHEA on endocrine functions of adipose tissue, the involvement of PPAR gamma. Biochem. Pharmacol., 70, 249-257 (2005).

20) Machinal F, Dieudonne MN, Leneveu MC, Pecquery R, Giudicelli Y. In vivo and in vitro ob gene expression and leptin secretion in rat adipocytes: evidence for a regional specific regulation by sex steroid hormones. Endocrinology, 140, 1567-1574 (1999).

21) Ruiz-Vela A, Aguilar-Gallardo C, Martínez-Arroyo AM, SorianoNavarro M, Ruiz V, Simón C. Specific unsaturated fatty acids enforce the transdifferentiation of human cancer cells toward adipocyte-like cells. Stem Cell Rev., 7, 898-909 (2011).

22) Kilgore MW, Tate PL, Rai S, Sengoku E, Price TM. MCF-7 and T47D human breast cancer cells contain a functional peroxisomal response. Mol. Cell. Endocrinol., 129, 229-235 (1997).

23) Singh RR, Gururaj AE, Vadlamudi RK, Kumar R. 9-cis-Retinoic acid up-regulates expression of transcriptional coregulator PELP1, a novel coactivator of the retinoid X receptor alpha pathway. J. Biol. Chem., 281, 15394-15404 (2006).

24) Wada T, Ihunnah CA, Gao J, Chai X, Zeng S, Philips BJ, Rubin JP, Marra KG, Xie W. Estrogen sulfotransferase inhibits adipocyte differentiation. Mol. Endocrinol., 25, 1612-1623 (2011).

25) Lea-Currie YR, Wen P, McIntosh MK. Dehydroepiandrosterone reduces proliferation and differentiation of 3T3-L1 preadipocytes. Biochem. Biophys. Res. Commun., 248, 497-504 (1998).

26) Dieudonne MN, Pecquery R, Leneveu MC, Giudicelli Y. Opposite effects of androgens and estrogens on adipogenesis in rat preadipocytes: evidence for sex and site-related specificities and possible involvement of insulin-like growth factor 1 receptor and peroxisome proliferator-activated receptor gamma2. Endocrinology, 141, 649-656 (2000).

27) Yeap BB, Krueger RG, Leedman PJ. Differential posttranscriptional regulation of androgen receptor gene expression by androgen in prostate and breast cancer cells. Endocrinology, 140, 3282-3291 (1999).

28) Bruedigam C, Koedam M, Chiba H, Eijken M, van Leeuwen JP. Evidence for multiple peroxisome proliferator-activated receptor gamma transcripts in bone: fine-tuning by hormonal regulation and mRNA stability. FEBS Lett., 582, 1618-1624 (2008).

29) Jennewein C, von Knethen A, Schmid T, Brüne B. MicroRNA-27b contributes to lipopolysaccharide-mediated peroxisome proliferatoractivated receptor gamma (PPARgamma) mRNA destabilization. $J$. Biol. Chem., 285, 11846-11853 (2010).

30) Jeong S, Yoon M. 17 $\beta$-Estradiol inhibition of PPAR $\gamma$-induced adipogenesis and adipocyte-specific gene expression. Acta Pharmacol. Sin., 32, 230-238 (2011).

31) Heinlein CA, Ting HJ, Yeh S, Chang C. Identification of ARA70 as a ligand-enhanced coactivator for the peroxisome proliferatoractivated receptor gamma. J. Biol. Chem., 274, 16147-16152 (1999).

32) Singh R, Artaza JN, Taylor WE, Braga M, Yuan X, Gonzalez-Cadavid NF, Bhasin S. Testosterone inhibits adipogenic differentiation in 3T3-L1 cells: nuclear translocation of androgen receptor complex with beta-catenin and T-cell factor 4 may bypass canonical Wnt signaling to down-regulate adipogenic transcription factors. Endocrinology, 147, 141-154 (2006).

33) Watanabe M, Inukai K, Katagiri H, Awata T, Oka Y, Katayama S. Regulation of PPAR gamma transcriptional activity in 3T3-L1 adipocytes. Biochem. Biophys. Res. Commun., 300, 429-436 (2003).

34) Perrey S, Ishibashi S, Yahagi N, Osuga J, Tozawa R, Yagyu H, Ohashi K, Gotoda T, Harada K, Chen Z, Iizuka Y, Shionoiri F, Yamada N. Thiazolidinedione- and tumor necrosis factor alphainduced downregulation of peroxisome proliferator-activated receptor gamma mRNA in differentiated 3T3-L1 adipocytes. Metabolism, 50, 36-40 (2001). 
35) Hauser S, Adelmant G, Sarraf P, Wright HM, Mueller E, Spiegelman BM. Degradation of the peroxisome proliferator-activated receptor gamma is linked to ligand-dependent activation. J. Biol. Chem., 275, 18527-18533 (2000).

36) van Beekum O, Fleskens V, Kalkhoven E. Posttranslational modifications of PPAR-gamma: fine-tuning the metabolic master regulator. Obesity (Silver Spring), 17, 213-219 (2009).

37) Bodles AM, Banga A, Rasouli N, Ono F, Kern PA, Owens RJ. Pioglitazone increases secretion of high-molecular-weight adiponectin from adipocytes. Am. J. Physiol. Endocrinol. Metab., 291, E1100E1105 (2006)

38) Nishizawa $H$, Shimomura $I$, Kishida $K$, Maeda N, Kuriyama $H$, Nagaretani H, Matsuda M, Kondo H, Furuyama N, Kihara S, Nakamura T, Tochino Y, Funahashi T, Matsuzawa Y. Androgens decrease plasma adiponectin, an insulin-sensitizing adipocyte-derived protein. Diabetes, 51, 2734-2741 (2002).

39) Xu A, Chan KW, Hoo RL, Wang Y, Tan KC, Zhang J, Chen B, Lam
MC, Tse C, Cooper GJ, Lam KS. Testosterone selectively reduces the high molecular weight form of adiponectin by inhibiting its secretion from adipocytes. J. Biol. Chem., 280, 18073-18080 (2005).

40) Iwaki M, Matsuda M, Maeda N, Funahashi T, Matsuzawa $Y$, Makishima M, Shimomura I. Induction of adiponectin, a fat-derived antidiabetic and antiatherogenic factor, by nuclear receptors. Diabetes, 52, 1655-1663 (2003).

41) Wu YG, Bennett J, Talla D, Stocco C. Testosterone, not $5 \alpha$-dihydrotestosterone, stimulates LRH-1 leading to FSH-independent expression of Cyp19 and P450scc in granulosa cells. Mol. Endocrinol., 25, 656-668 (2011).

42) Saleh J, Al-Wardy N, Farhan H, Al-Khanbashi M, Cianflone K. Acylation stimulating protein: a female lipogenic factor? Obes. Rev., 12, 440-448 (2011).

43) Pedersen SB, Kristensen K, Richelsen B. Anti-glucocorticoid effects of progesterone in vivo on rat adipose tissue metabolism. Steroids, 68, 543-550 (2003). 